\title{
Assessment of oils of selected legumes and oil plants with regard to animal nutrition
}

\author{
Lucie Rusníková1, Eva Straková1, Pavel Suchý \\ ${ }^{1}$ University of Veterinary and Pharmaceutical Sciences Brno, Faculty of Veterinary Hygiene and Ecology, \\ Department of Animal Nutrition, Brno, Czech Republic \\ ${ }^{2}$ University of Veterinary and Pharmaceutical Sciences Brno, Faculty of Veterinary Hygiene and Ecology, \\ Department of Animal Husbandry and Animal Hygiene, Brno, Czech Republic \\ Received February 14, 2013 \\ Accepted May 29, 2013
}

\begin{abstract}
The aim of our study was to compare nutritional quality of oils of legumes (soybean, pea, faba bean and lupin) and oil plants (rape, sunflower, poppy and flax) grown in the Czech Republic. Individual seeds of legumes and oil seeds were analysed for fat content and fatty acid profile. Fatty acids were detected by gas chromatography, following fat extraction. The fatty acid profile was evaluated for contents of fatty acids saturated, unsaturated, monounsaturated, polyunsaturated, n-3 and n- 6 fatty acids. The highest proportion of fat in the dry matter of seed was found in poppy, followed by sunflower, flax, rape, soybean, lupin, pea, and faba bean. Differences in fat contents between individual plants were highly significant $(P \leq 0.01)$, except for differences between flax and rape $(P \leq 0.05)$, pea and faba bean and poppy and sunflower (non-significant). Apart from rapeseed, markedly higher proportions of polyunsaturated fatty acids were found in other oils but rapeseed had the least content of saturated fatty acids. Legumes had a favourable ratio of n-3:n-6 fatty acids, especially lupin oil (1:4.3), which is in accordance with the recommended ratio 1:5. Sunflower oil is less suitable, with n-3 present in trace concentration. The most significant source of $n-3$ is flaxseed oil. The study brings new findings regarding oil composition in a wide range of feed components. These data may be used for development of diets for specific purposes and for production of functional food.
\end{abstract}

Fat content, fatty acid, PUFA, n-3, n-6, n-9

Legume seeds contain small amounts of fat and are not grown for the purpose of fat extraction like oilseeds, with the exception of soybean. The fat content in legumes has been studied by a number of authors (Karaaslan 2008; Campos-Vega et al. 2010; Chiofalo et al. 2012); and so has the composition of oilseeds (Eriksson et al. 1994; Bozan and Temelli 2003, 2008; Özcan and Atalay 2006). Oils contained in legumes, although less discussed, might perform an important nutritional role regarding their fatty acid (FA) profile. An important criterion for oil assessment for dietary purposes is represented by the contents and mutual proportions of fatty acids (FA): saturated fatty acids (SFA) and unsaturated fatty acids (UFA). The quality of fat is most revealed by monounsaturated (MUFA) and polyunsaturated (PUFA) fatty acid contents. These groups include essential fatty acids which are important for both human and animal nutrition.

Recommendations for human diet are as follows: fat should represent $15-30 \%$ of the overall energy intake, of which saturated fatty acids should account for less than $10 \%$, polyunsaturated fatty acids for $6-10 \%, n-6$ for $5-8 \%, n-3$ for $1-2 \%$, and trans fatty acids for less than 1\% (Krejčí-Treu et al. 2010). Special emphasis is laid on sufficient intake of n-3 FA and mutual proportion of n-3 FA:n-6 FA in the diet. The recommended ratio is 1:5 (Straková et al.2008). Fatty acid profiles of various oils are monitored but a more extensive survey of fatty acid profiles of legumes and oil plants grown in the moderate climate of central Europe is still missing. Different authors have analysed profiles of fatty acids in different oilseeds. Perez et al. (2004) and Sabudak (2007) analysed sunflower seeds, Bayrak et al. (2010) analysed different cultivars of flax, while El-Beltagi and Mohamed 
(2010) analysed FA composition in different cultivars of rape. Özcan and Atalay (2006) focused on poppy. Bozan and Temelli (2003) obtained oil from poppy by an untraditional method. Legume seeds are mainly considered a quality source of nitrogenous substances and their positive fat compositions are often neglected (Wood and Fearon 2009). Erbas et al. (2005) and Sujak et al. (2006) analysed different lupin species, Karaaslan (2008) analysed soybean. Jezierny et al. (2010) tested different legumes. The authors also studied the effects of climate and environmental conditions on FA proportions, such as growing in dry climates or on different continents (Karaaslan 2008; Zheljazkov et al. 2009). The effect of different feed supplementations on the fatty acid profile of the product - meat and eggs is also frequently studied (Krejčí-Treu et al. 2010; Hudečková et al. 2012; Kralik et al. 2012). Nevertheless, general assessment of the most often used legumes and oil plant seeds under moderate climatic conditions is missing. These values may be found useful for development of animal diets with regard to fatty acid profile.

The aim of this study was to compare a dietetic and nutritional quality of oils of selected seeds of major legumes and oil plants grown in the Czech Republic.

\section{Materials and Methods}

Specimens of seeds of individual species of legumes and oil plants were provided by the Central Institute for Supervising and Testing in Agriculture (Brno, Czech Republic).

The tested seeds included winter rapeseed (Brassica napus) including 26 cultivars from two stations (Artus, Laser, Aviso, Extra, Lisek, Baros, Executive, Vectra, Banjo, Dubai, Oponent, Navajo, Jesper, Catonic, Liprima, Viking, Baldur, Slogan, Smart, Californium, Caracas, Labrador, Manitoba, Winner, Siska, Digger), annual sunflower seed (Helianthus annuиs) including 24 cultivars (Orasole, Heliaroc, Labud, Pomar RM, Parma, Belem M, Allium, NK Brio, Alexandra, Jolly, Alisson, PRG3A82, Barolo RM, Oxana, Kongo, Gen 2000, ES Baila, ES Lolilta, Opera, Melody, Tellia, PR 64H61, PR 64A63 a Pegasol), flaxseed (Linum usitatissimum) including 12 cultivars of 7 fibre varieties (Jordan, Bonet, Jitka, Tábor, Marylin, Venica, Agatha) and 5 oil varieties (Flanders, Jantar, AGT 248, Lola, Biltstar) and poppy seed (Papaver somniferum) including 3 cultivars (Gerlach, Opal, Sokol).

The analysed legumes included seeds of soybean (Soja hispida) including 10 cultivars (Rita, Tundra, Moravians, Moravians 2, Quito, Quito 2, Korada, Bohemians, OAC Vision, OAC Erin), green pea (Pisum sativum) including 11 cultivars (Zekon, Herold, Sponsor, Hardy, Terno, Baryton, Tudor, Concorde, Prophet, Slovan, Sully), faba bean (Faba vulgaris) including 10 cultivars (Carola, Gloria, Borek, Merkur, Stabil, Albi, Mistral, Amazon, Merlin, Fuego) and lupin (Lupinus sp.) including 9 cultivars (Amiga, Boregine, Bornal, Boruta, LAL 1, Oležka, Probor, Wodsil, APR 82).

The specimens were analysed in the laboratories of the Department of Animal Nutrition, University of Veterinary and Pharmaceutical Sciences Brno. Dry matter contents $\left(\mathrm{g} \cdot \mathrm{kg}^{-1}\right)$ were specified in the legume seeds and oil seeds following their grinding and homogenisation. Fat was extracted from the prepared sample by Soxhlet method (ČSN EN ISO 659) to obtained $200 \mathrm{mg}$. The extracted fat $(80 \mathrm{ml})$ was transformed to esters, and concentrations of fatty acids in the form of methyl-esters (FAMEs) were specified by gas chromatography, analyzer GC-2010 (Shimadzu, Japan) with flame ionization detector (FID). The method with an addition of internal standard (C15:0) was used. The GC-2010 system was equipped with an auto sampler and auto injector. The injection volume was $1 \mu \mathrm{l}$. The total split flow was $90 \mathrm{ml} / \mathrm{min}$. Helium was used as the carrier gas. Air and hydrogen were used as auxiliary gases. The FAMEs were separated on a column VB-VAX (60 m length; $0.25 \mathrm{~mm}$ ID; $0.25 \mu \mathrm{m}$ film thickness). The FID temperature was set at $300^{\circ} \mathrm{C}$, initial injector temperature was $280{ }^{\circ} \mathrm{C}$ and pressure was $299.2 \mathrm{kPa}$, initial column temperature was $70{ }^{\circ} \mathrm{C}$. The data were processed by a computer using data processor GC soution Postrun.

Statistical evaluation of chemical analysis results were carried out using the Unistat program (5.6 for Excel), at the levels of significance $P \leq 0.01$ (highly significant difference) and $P \leq 0.05$ (significant difference). The achieved results were used for assessment of appropriateness of use of the individual oils in animal nutrition.

\section{Results}

Table 1 indicates the fat content in legumes and oil plant seeds expressed in $\mathrm{g}^{\mathrm{kg}} \mathrm{g}^{-1}$ of dry matter. Oil seeds contained much higher oil levels than legume seeds. Differences between individual plant types were highly significant $(P \leq 0.01)$, except for the difference between flax and rape $(P \leq 0.05)$, green pea and faba bean, poppy and sunflower, which were nonsignificant. Fatty acids in the oil of legumes and oil seeds were in the highest proportions, 
namely palmitic, stearic, oleic/elaidic, linoleic/linolelaidic, $\alpha$-linolenic, arachidic, cis-11eicosenoic and behenic (C16:0, C18:0, C18:1, C18:2, C18:3n3, C20:0, C20:1, C22:0, respectively) and the FA whose concentrations are monitored due to its negative effects on animal health - eruicic acid (C22:1). The most frequent fatty acids in legumes and oil seeds included $\mathrm{C} 18: 1$ and $\mathrm{C} 18: 2$. The highest content of $\mathrm{C} 18: 1$ was found in rapeseed compared to other legumes and oil plants $(P \leq 0.01)$. In legumes, the highest content of $\mathrm{C} 18: 1$ was detected in lupin compared to other legumes and oil plants $(P \leq 0.01)$, except for sunflower seed $(P \leq 0.05)$. The highest contents of $\mathrm{C} 18: 2$ were detected in poppy seed and soybean $(P \leq 0.05)$. The differences in $\mathrm{C} 18: 2$ concentrations in poppy seed and other legumes and oil plants were highly significant $(P \leq 0.01)$. The difference in $C 18: 2$ concentrations in soybean was highly significant $(P \leq 0.01)$ only in comparison to rapeseed, flaxseed and lupin. Flaxseed contained the highest concentrations of $\mathrm{C} 18: 3 \mathrm{n} 3(P \leq 0.01)$ compared to other legumes and oil seeds. Higher contents of $\mathrm{C} 18: 3 \mathrm{n} 3$ were also found in legumes, especially in green pea, which even exceeded the concentrations in some oil seeds. The highest content of $\mathrm{C} 22: 1$ was found in lupin compared to other legumes and oilseeds $(P \leq 0.01)$.

Table 1. Concentrations of fatty acids most frequently present in oil of legumes and oil plant seeds and fat content in the seed dry matter

\begin{tabular}{|c|c|c|c|c|c|c|c|c|}
\hline $\begin{array}{c}\begin{array}{c}\text { Fatty } \\
\text { acids }\end{array} \\
\left(\mathrm{g} \cdot 100 \mathrm{~g}^{-1} \text { oil }\right) \\
\end{array}$ & $\begin{array}{c}\text { Oil } \\
\text { Lupin }\end{array}$ & Soybean & Pea & Faba bean & Flax & Poppy & Rape & Sunflower \\
\hline $\mathrm{C} 16: 0$ & $7.25 \pm 2.18$ & $9.96 \pm 0.55$ & $7.57 \pm 0.38$ & $9.08 \pm 0.74$ & $4.90 \pm 0.86$ & $8.45 \pm 0.03$ & $4.30 \pm 0.31$ & $4.78 \pm 0.60$ \\
\hline C18:0 & $3.28 \pm 1.92$ & $3.49 \pm 0.41$ & $2.45 \pm 0.22$ & $2.00 \pm 0.16$ & $3.48 \pm 0.75$ & $2.03 \pm 0.10$ & $1.73 \pm 0.19$ & $3.62 \pm 0.59$ \\
\hline C18:1 & $37.37 \pm 11.92$ & $18.94 \pm 1.99$ & $17.50 \pm 2.00$ & $17.89 \pm 1.41$ & $15.06 \pm 2.41$ & $12.97 \pm 0.92$ & $63.47 \pm 2.69$ & $28.62 \pm 13.97$ \\
\hline $\mathrm{C} 18: 2$ & $35.72 \pm 10.06$ & $52.09 \pm 3.81$ & $37.81 \pm 2.93$ & $42.97 \pm 1.69$ & $27.06 \pm 21.97$ & $72.27 \pm 1.68$ & $17.24 \pm 1.76$ & $50.46 \pm 12.57$ \\
\hline C18:3n3 & $8.33 \pm 3.91$ & $8.51 \pm 1.22$ & $12.13 \pm 2.77$ & $4.06 \pm 0.41$ & $38.00 \pm 21.88$ & $0.93 \pm 0.12$ & $6.60 \pm 0.76$ & $0.08 \pm 0.01$ \\
\hline $\mathrm{C} 20: 0$ & $1.15 \pm 0.95$ & $0.31 \pm 0.05$ & $0.50 \pm 0.04$ & $1.33 \pm 0.17$ & $0.16 \pm 0.04$ & $0.09 \pm 0.01$ & $0.56 \pm 0.06$ & $0.27 \pm 0.04$ \\
\hline $\mathrm{C} 20: 1$ & $2.03 \pm 1.97$ & $0.16 \pm 0.03$ & $0.40 \pm 0.06$ & $0.52 \pm 0.02$ & $0.15 \pm 0.02$ & $0.08 \pm 0.01$ & $1.02 \pm 0.07$ & $0.14 \pm 0.03$ \\
\hline $\mathrm{C} 22: 0$ & $3.06 \pm 1.98$ & $0.33 \pm 0.04$ & $0.15 \pm 0.02$ & $0.63 \pm 0.14$ & $0.11 \pm 0.02$ & $0.01 \pm 0.01$ & $0.28 \pm 0.07$ & $0.64 \pm 0.07$ \\
\hline $\mathrm{C} 22: 1$ & $0.69 \pm 0.75$ & ND - & $0.11 \pm 0.02$ & $0.03 \pm 0.01$ & ND & ND & $0.04 \pm 0.06$ & ND \\
\hline $\begin{array}{l}\text { Fat } \\
\left(\mathrm{g} \cdot \mathrm{kg}^{-1}\right)\end{array}$ & $56.32 \pm 11.16$ & $201.15 \pm 20.98$ & $7.35 \pm 2.71$ & $4.77 \pm 1.46$ & $401.70 \pm 30.69$ & $494.43 \pm 12.75$ & $372.10 \pm 35.87$ & $486.84 \pm 28.20$ \\
\hline
\end{tabular}

Data are expressed as $\mathrm{x} \pm \mathrm{SD}\left(\mathrm{g} \cdot 100 \mathrm{~g}^{-1}\right.$ oil $), \mathrm{SD}$ - standard deviation, ND - not detected, C16:0 - palmitic, C18:0 - stearic, C18:1 - oleic/elaidic, C18:2 - linoleic/linolelaidic, C18:3n3 - $\alpha$-linolenic, C20:0 - arachidic, C20:1 - cis-11-eicosenoic, C22:0 - behenic, $\mathrm{C} 22: 1$ - eruicic acid

For the purpose of the analysis, fatty acids were classified as SFA and UFA including MUFA and PUFA. The PUFA were further divided into n-3 and n-6 FA and their proportion was expressed as shown in Table 2. The quantities of UFA, as assumed, prevailed over SFA in both legumes and oilseeds. Rapeseed oil contained the lowest concentrations of SFA. Legumes showed higher proportions of SFA. In the case of lupin oil a significant difference was found in MUFA (40\%) and PUFA (44\%). In the other oils, the MUFA/PUFA ratios were significantly different between individual plant species; in rape oil MUFA prevailed $(65 \%)$, whereas in the other analysed oils it was PUFA that prevailed with the highest concentrations in poppy seed $(73 \%)$. 
Table 2. Fatty acid groups in the oil of legumes and oil seeds

\begin{tabular}{|c|c|c|c|c|c|c|c|}
\hline \multirow{2}{*}{ Oil } & \multicolumn{7}{|c|}{ Group of fatty acids $\left(\mathrm{g} \cdot 100 \mathrm{~g}^{-1}\right.$ oil $)$} \\
\hline & SFA & UFA & MUFA & PUFA & n-6 FA & n-3 FA & $n-3 / n-6$ \\
\hline Lupin & 15.89 & 84.66 & 40.33 & 44.33 & 35.96 & 8.37 & 0.23 \\
\hline Soybean & 14.46 & 79.86 & 19.21 & 60.65 & 52.14 & 8.51 & 0.16 \\
\hline Pea & 11.51 & 68.28 & 18.21 & 50.07 & 37.94 & 12.13 & 0.32 \\
\hline Faba bean & 14.46 & 65.75 & 18.53 & 47.23 & 43.17 & 4.06 & 0.09 \\
\hline Flaxseed & 9.00 & 80.59 & 15.29 & 65.30 & 27.25 & 38.04 & 1.40 \\
\hline Poppy seed & 10.77 & 86.44 & 13.21 & 73.23 & 72.30 & 0.93 & 0.01 \\
\hline Rapeseed & 7.13 & 88.80 & 64.89 & 23.90 & 17.30 & 6.60 & 0.38 \\
\hline Sunflower & 9.65 & 79.38 & 28.84 & 50.54 & 50.46 & 0.08 & 0.00 \\
\hline
\end{tabular}

SFA - saturated fatty acids, UFA - unsaturated fatty acids, MUFA - monounsaturated fatty acids, PUFA - polyunsaturated fatty acids, FA fatty acids

\section{Discussion}

The fat content in soybean seed exceeded fat contents in the other legume seeds. Results of fat contents are similar to those published by Karaaslan (2008). In our study, low fat values in faba bean and pea were detected, which contradicts the findings of Jezierny, Mosenthin and Bauer (2010), and Campos-Vega et al. (2010). Unlike Jezierny et al. (2010), we detected oleic and linoleic acids as the top-level FAs in faba bean. The other authors do not report increased concentrations of $\mathrm{C} 18: 3 \mathrm{n} 3$ in legumes as we found in our analysis, especially in pea, where the concentrations were higher than in some of the oilseeds. In our study, lupin differed from faba bean and pea with higher fat concentrations. In lupin the individual fatty acid concentrations were strongly influenced by the variety, but on average the prevailing FA included oleic and linoleic acids, which is also confirmed by Jezierny et al. (2010). Similar results as in our study concerning fat and FA concentrations in lupin were published (Erbas et al. 2005; Sujak et al. 2006; Chiofalo et al. 2012). These authors focused on the individual lupin species (L. luteus, L. angustifolius and L. albus). In our study, the highest contents of SFA were detected in L. angustifolius, whereas L. luteus showed top concentrations of n-6 PUFA. L. albus showed the highest $\mathrm{n}-3 / \mathrm{n}-6$ FA ratio, which corresponds to the results published by Chiofalo et al. (2012) who considered L. luteus promising for growing in Europe and mentioned L. albus as the most interesting with regard to human and farm animal nutrition, which was also confirmed by Sujak et al. (2006). Negative features of lupin may include the highest concentrations of eruicic acid of all analysed plants. In the analysed oilseed group, rapeseed contained the lowest concentration of oil in dry matter. Erikss on et al. (1994) detected higher values of oil in winter rape. In our study, $\alpha$-linoleic acid content in rapeseed was lower than reported by El-Beltagi and Mohamed (2010). We found the highest concentrations of oil per $1 \mathrm{~kg}$ of dry matter in poppy seed of all plants. The lower values reported by other authors may be due to different methods of extraction (Bozan and Temelli 2003) or different poppy cultivars (Özcan and Atalay 2006). We found C18:2 to be the prevailing FA in poppy seed, and its concentrations in poppy seed were the highest of all plants, which was also confirmed by other authors (Nergiz and Ötles 1994; Bozan and Temelli 2003, 2008; Özcan and Atalay 2006). In sunflower seed we found significant differences in fatty acid contents between its cultivars (C18:1 and C18:2), which may be influenced by various agronomic factors, as mentioned by Zheljazkov et al. (2009). Their concentrations are, however, comparable to the results of other authors (Perez et al. 2004; Sabudak 2007). We found C18:3n3 acid in trace concentrations in all sunflower cultivars, which 
is unfavourable from the dietetic point of the view. Flax contained the highest contents of $\mathrm{C} 18: 3 \mathrm{n} 3$ in comparison to other legumes and oil plants, as assumed by Bozan and Temelli (2008). We found considerable differences in C18:3n3 concentrations between cultivars, in particular between types grown for spinning and for oil, where the former reached considerably higher values on average. Similar results depending on the cultivar were also found by Bayrak et al. (2010). Not only the variety but also the sowing interval may affect the flax oil composition, as was found by Endes et al. (2012). According to recommendations by Krejčí-Treu et al. (2010), flax, rape and sunflower seed oils were the most suitable oils with the SFA content less than 10\%; rapeseed oil had the best concentrations of n-6 FA (17.3\%) and n-3 FA (6.6\%). The n-3/n-6 FA ratio is 0.38 in rapeseed oil which is higher than recommended by Straková et al. (2008). Other studied oils had very high levels of PUFA, which did not correspond with the recommendation. In any case, it is important to take into account that animal and human diets do not consist of one type of fat.

Legumes displayed a suitable n-3:n-6 FA ratio, especially in lupin seed oil (1:4.3). Sunflower seed oil is less suitable from the dietetic point of view, because n-3 FA are present in trace concentrations, as in poppy seed oil. The most significant source of n-3 FA is flaxseed oil. The results of the analyses lead to the conclusion that legume seed oils are suitable both for human and animal nutrition. Regarding the n-3 and n- 6 FA ratio, they appear even more appropriate than some of the oilseeds used in the study.

\section{Acknowledgements}

This study was funded by the grant IGA 5/2012/FVHE.

\section{References}

Bayrak A, Kiralan M, Ipek A, Arslan N, Cosge B, Khawar KM 2010: Fatty acid compositions of linseed (Linum usita tissimum 1.) genotypes of different origin cultivated in Turkey. Biotechnol Biotec Eq 24: 1836-1842

Bozan B, Temelli F 2003: Extraction of poppy seed oil using supercritical $\mathrm{CO}_{2}$. J Food Sci 68: 422-426

Bozan B, Temelli F 2008: Chemical composition and oxidative stability of flax, safflower and poppy seed and seed oils. Bioresource Technol 99: 6354-6359

Campos-Vega R, Loarca-Piňa G, Oomah DB 2010: Minor components of pulses and their potential impact on human health. Food Res Int 43: 461-482

Chiofalo B, Presti LV, Chiofalo V, Gresta F 2012: The productive traits, fatty acid profile and nutritional indices of three lupin (Lupinus spp.) species cultivated in a Mediterranean environment for the livestock. Anim Feed Sci Tech 171: 230-239

ČSN EN ISO 659 (461034): Oilseeds - Determination of oil content (Reference method). Praha: Czech Office for Standards, Metrology and Testing, 2011. ICS 67.200.20

El-Beltagi HEDS, Mohamed AA 2010: Variations in fatty acid composition, glucosinolate profile and some phytochemical contents in selected oil seed rape (Brassica napus L.) cultivars. Grasas Y Aceites 61: 143-150

Endes Z, Akinerdem F, Ozcan MM 2012: Determination of saturated and unsaturated fatty acids by gas chromatography in linseed (Linum usitatissimum L.) genotypes. Asian J Chem 24: 2221-2224

Erbas M, Certel M, Uslu MK 2005: Some chemical properties of white lupin seeds (Lupinus albus L.). Food Chem 89: 341-345

Eriksson I, Westerlund E, Aman P 1994: Chemical-composition in varieties of rapeseed and turnip rapeseed, including several samples of hull and dehulled seed. J Sci Food Agr 66: 233-240

Hudečková P, Rusníková L, Straková E, Suchý P, Marada P, Macháček M 2012: The effect of lenseed oil supplementation of the diet on the content of fatty acids in the egg yolk. Acta Vet Brno 81: 159-162

Jezierny D, Mosenthin R, Bauer E 2010: The use of grain legumes as a protein source in pig nutrition: A review. Anim Feed Sci Tech 157: 111-128

Karaaslan D 2008: Determination of total protein and fatty acid composition of soybean seed as affected by sowing dates. Asian J Chem 20: 767-775

Kralik Z, Kralik G, Grčević M, Suchý P, Straková E 2012: Effects of increased content of organic selenium in feed on the selenium content and fatty acid profile in broiler breast muscle. Acta Vet Brno 81: 31-35

Krejčí-Treu T, Straková E, Suchý P, Herzig I 2010: Effect of vegetable oil fortified feeds on the content of fatty acids in breast and thigh muscles in broiler chickens. Acta Vet Brno 79: 21-28

Nergiz C, Ötles S1994: The proximate composition and some minor constituents of poppy seeds. J Sci Food Agr 66: $117-120$ 
Özcan MM, Atalay C 2006: Determination of seed and oil properties of some poppy (Papaver somniferum L.) varieties. Grasas Aceites 57: 169-174

Perez EE, Carelli AA, Crapiste GH 2004: Chemical characterization of oils and meals from wild sunflower (Helianthus petiolaris Nutt). J Am Oil Chem Soc 81: 254-249

Sabudak T 2007: Fatty acid composition of seed and leaf oils of pumpkin, walnut, almond, maize, sunflower and melon. Chem Nat Compd 43: 465-467

Straková E, Suchý P, Herzig I, Staňa J, Zehnálek P 2008: Dietary importance of fatty acids in the nutrition of animals and human. Veterinářství 11: 708-712

Sujak A, Kotlarz A, Strobek W 2006: Compositional and nutritional evaluation of several lupin seeds. Food Chem 98: 711-719

Wood VB, Fearon AM 2009: Dietary sources of unsaturated fatty acids for animals and their transfer into meat, milk and eggs: A review. Livest Sci 126: 1-20

Zheljazkov VD, Vick BA, Baldwin BS, Buehring N, Astatkie T, Johnson B 2009: Oil content and saturated fatty acids in sunflower as a function of planting date, nitrogen rate, and hybrid. Agron J 101: 1003-1011 